\title{
Exploring Mixed-methods Instruments for Performance Evaluation of Immersive Collaborative Environments
}

Laurent Dupont 1, Marc Pallot 2, Laure Morel 1, Olivier Christmann 2, Vincent Boly 1, Simon Richir 2

1 Université de Lorraine, ERPI, 8 Rue Bastien Lepage, 54000 Nancy, France

2 Arts et Métiers ParisTech, LAMPA, 2 bd du Ronceray, 49000 Angers France

Contact author: 1.dupont@univ-lorraine.fr

Abstract - Presently, there is a clear trend for both businesses and public institutions to move towards open or collaborative innovation. Nevertheless, engaging all stakeholders, especially users, for cocreating innovative solutions and usage scenarios is, as revealed in previous studies, not so obvious. We do believe that Immersive and Collaborative Environments (ICEs) based on the use of Virtual, Augmented and Mixed Reality technologies would be the right place for co-creating, exploring, experimenting and evaluating innovative ideas and concepts in order to quickly reach a common understanding. However, there is a need to design a proper method and instruments that would allow evaluating and comparing ICEs. Our previous paper presented the outcomes of an investigation to identifying and disentangling factors characterising a group immersion and collaboration in the context of co-creation. As a step further, this paper reports about our exploratory study towards the design of mixed methods quantitative and qualitative instruments for the evaluation of Immersive and Collaborative Environments (ICE) based on previously identified factors.
Index Terms - Immersive Virtual Environment; Virtual/Augmented/Mixed Reality; Collaborative Innovation; Mixed Methods; Performance Measurement; User/Immersive/collaborative eXperience.

\section{INTRODUCTION}

Innovation processes are more and more collective [1], [2]. Co-creation is one of the most important activities for designing innovative ideas and usage scenarios, through an iterative eXperience Design process, with users. It allows to anticipate the resulting User eXperience; hence, evaluating the potential technology acceptance and solution adoption by users. This is an essential difference with users observation-based design approaches like contextual design or even design thinking.

In this paper, we present the continuation of our previous work [3], [4] on Immersive Virtual Environments (IVE) towards the design of a specific framework for experimenting and evaluating Immersive Collaboration/Co-creation Environments (ICE). Such kind of immersive environments intended for several users has been, up-tonow, often implemented through the use of a CAVE. However, CAVE solutions are not so affordable for SMEs or Start-ups. Recently, low-cost immersive technologies have emerged, which further explains why we want to experiment and evaluate different ICE 
platforms that could be more affordable for small organizations. Besides discussing the research publication stream on ICE, we explore the previous work related to immersive collaboration within the context of Virtual Reality (VR), Augmented Reality (AR) and Mixed Reality (MR) technologies. Our goal is to identify and disentangle factors impacting immersive co-creation in the view of preparing appropriate experiments and related evaluation approaches.

\section{PREVIOUS WORK}

We have previously [4], [5] introduced most of the concepts used in this work, such as: Open/ Collaborative Innovation, User-Driven Innovation (UDI), Living Lab, Immersive Technologies (VR, AR, MR), eXperience Design (XD), Co-creation, Collective User eXperience (CUX), Immersive eXperience (IX), Quality of Service (QoS) and Quality of Experience (QoE). Our UDI vision fits with the Von Hippel studied "Consumer Innovation" paradigm [5].

\subsection{Co-creation}

Ramaswamy and Gouillart [6] consider that Co-creation is about engaging people to create more value together and involves redesigning interactions based on individuals' experiences. They argue that through cocreation, organizations can unleash the creative energy of people - especially employees and internal stakeholders, but also customers, suppliers, and related external stakeholders and communities - to create mutual value. The term "co-creation" is a typical design collaboration activity synonymous to ideation but refers to the engagement of customers/users/citizens for co-creating value [4]. Furthermore, cocreation is a group activity, based on social interaction, which implies the notion of copresence (or social presence) when it occurs in immersive environments. Hence, cocreation is one of the activities characterising User-Centred Design (UCD) methods, such as eXperience Design (XD).

When a group of participants representing different disciplines and stakeholders have to collaborate, distance factors affect their collaboration performance [7]. One could argue that it is exactly the same for cocreation in immersive environments because it is just a particular form of collaboration involving users as experts of usage scenarios. For example, interpersonal distance is a wellidentified factor impeding collaboration effectiveness and efficiency between humans [8] or between humans and virtual humans [9] within an immersive environment.

Scholars have studied co-creation and a related form of social immersion. Pallot et al. [30] argue that innovation paradigms and design approaches promote distributed collaboration among organisations and user communities. However, project stakeholders are mainly trained for improving their individual skills through learning experience (i.e. practical exercises, role playing game) rather than getting a live user experience through immersive environments (e.g. Virtual Reality, Serious Games) that could unleash their creativity potential. Authors discuss issues related to the use of innovation games for enabling user co-creation in the context of collaborative innovation and experiential living labs. They also argue that people are trained for enhancing their individual skills and improving their productivity rather than for enhancing their collaboration skills and improving their interpersonal productivity. On the one hand, users or citizens have to experience something new while sharing feedback, meaning and understanding within the community; on the other hand, researchers collect data for better understanding emerging behaviours and usage patterns as well as embedded adoption mechanisms. Authors try to evaluate the role of distributed cognition and collective intelligence, including both social and emotional intelligence in the decision making process. Recently, Rihova et al. [10] introduce a Customer-to-Customer (C2C) co-creation perspective, conceptualizing the social layers within which value is formed. This approach extends current value co-creation discussions by providing conceptual insights into co-creation 
within customers' social sphere; hence, allows benefiting from understanding how customers can be "nudged" into more socially immersive co-creation layers.

\subsection{Immersion}

According to the Oxford dictionary, the term 'immersion' means "the action of immersing someone or something in a liquid" or "deep mental and social involvement in something" like the very famous "learning by immersion: a method of teaching a foreign language by the exclusive use of that language". Therefore, one could conclude that there is a notion of physical immersion, a notion of mental immersion and a notion of cultural/social immersion. According to Freina and Ott, immersive environments in education have been mainly deployed in the area of educational games due to expensiveness of immersive technology platforms and limited usability [11]. They investigate the scientific literature, over 201314 , on the advantages and potentials of using immersive environments in Education. Brown and Cairns [12] consider that immersion is a graded experience that progresses through degrees of engagement.

As mentioned by Nordin et al. [13], [14], concepts such as fun, flow, presence and immersion have been widely used to describe the digital games user's experience. According to these authors, both Brockmyer et al. "Gaming Engagement Questionnaire" (GEQ) [15] and Jennett et al. "Immersive Experience Questionnaire" (IEQ) [16] are relevant examples of questionnaires for evaluating digital games user's experience. The IEQ has been applied in different scenarios and game types [17]-[19]. While Nordin and colleagues considered including Usability [20] in their future work, the Social Presence Questionnaire [21] that appears in their review of existing relevant questionnaires is not included.

\subsection{Immersive Platform}

According to Pallot et al. [22], an immersive platform is composed of both assembled immersive technologies (hardware and software) and a specific 3D content application. This kind of platform represents the technological facet of an IVE. They consider that an IVE encompasses 3 different but complementary perspectives, namely: the physical implementation of the immersive technologies, the resulting Immersive eXperience (IX) representing a specific form of UX and an evaluation framework for assessing all factors constituting the overall performance.

The IVE structure is composed of Immersive technologies (VR, AR, MR) and Immersive (3D) Content delivering an IX to users. The resulting perceived sensations are then evaluated through IX's factors. Measured QoS technical factors (e.g. Fieldof-view, frame-rate, resolution and latency factors) and evaluated QoE factors (e.g. easeof-use, usefulness, presence) allow to assess the overall quality of the resulting IX. However, the degree of immersiveness varies also according to the type of used technologies (AR, VR, MR) and goals of the immersive application [22].

Based on reviewed publications in [22], Pallot and Richir argue that immersion represents the state of being deeply engaged (e.g. swimming), recognised as a tactical/sensorymotoric immersion; or fully absorbed in solving a problem (e.g. playing chess), seen as a strategic/cognitive immersion; or reading a captivating story or watching an exciting movie, considered as a narrative/emotional immersion. These types of immersion make one's brain so busy that everything else around simply disappears; Nordin et al. [13] refer this phenomenon to real-world dissociation. A pretty good way to measure the deepness to which a person is engaged is to observe whether time passes without being noticed and whether external world disappears. To make it short, one could argue that a $360^{\circ} \mathrm{VR}$ immersion bubble operates like a mind-blowing teleportation, instantaneously transporting a user in an existing remote place or a different world that is persistent enough to become another reality, even if it is a virtual one. 
Innovation platforms also generate knowledge, practices and practical knowhows. The Lorraine Fab Living $\mathrm{Lab}^{\circledR}$, the ERPI research platform for prospective assessment of innovative usages and innovation acceptability develops "low cost" Immersive Collaborative Environments supporting front end innovation development since 2014 [4], [23]. According to our experience and our previous Living Lab (LL) projects involving various stakeholders or communities in collaborative approach [3], [24] we learnt that it is necessary to propose different degree of technological devices. Indeed, LL participants don't have the same backgrounds, knowledge and motivations. If we want to include the largest number of stakeholders in collaborative approach supported by technologies, we have to consider their different capacities to understand and use relevant new technologies. For example, Figure 1 shows the implementation for running experiments of four different immersive environments for co-creative workshops (ICEs): the Computer Screen platform (a), the collaborative interfaces on Multitouch Tables platform (b), an original collective user experiences inside one Immersive Bubble platform (c). Researchers also develop experiments with two different Head Mounted Display (HMD) platforms and its ad hoc virtual contents (d). A previous scientific paper [4] presents the technical descriptions for (b) \& (c) and how all these technologies work in a complementary manner in the LF2L platform. Pictures and video are available online at: https://flic.kr/p/U114Zu. As we adopt different technological levels, we assume that these platforms don't offer the same degree of immersiveness and VR/AR/MR as well as 3D content developments. This diversity of tools reduces dependence on a specific technology and generates a higher degree of freedom to approach collectively fuzzy front end of innovation and co-creation processes.

\subsection{Social Immersion}

While 'Social Interaction' and 'Social Presence' are quite well established constructs in both IVE and ICE empirical studies [25]-[27], the 'Social Immersion' or 'Social Immersive' perspective is rarely mentioned excepted in the areas of Interactive Storytelling and Massive Multiplayer Online Roleplaying Games (MMORPGs) [28]-[31]. Such a social immersion or social immersive perspective characterises a 'Socially Immersive eXperience' (SIX) [31]. In the collaboration research area, the constructs of 'Interpersonal Distance' [9], [22] and 'Interpersonal Trust' [32] represent the people capacity to interact together in a virtual environment whatever barrier separates them (e.g. remote places, lack of confidence). Previous empirical studies revealed that the interpersonal or trust distance hinders the social presence. Other Scholars have been studying social inhibitors in IVE [33].

\subsection{Immersion and collaboration}

There are mainly two publication streams dedicated to immersive co-creation, namely: Immersive Collaborative environments (ICE) and Collaborative Virtual Environments (CVE). There are numbers of empirical studies on different immersive technology platforms that were conducted through experiments involving several participants (see Table 1).

\section{Resulting ICE Model and Structure}

\subsection{ICE Model based on four Immersive} Facets

Our main goal is to experiment and assess the performance of different immersive environments in the context of co-creation with users/customers/citizens. Therefore, we had to turn the IVEs into ICEs and include the multi-user context in the usage scenario. Figure 2 presents an ICE tentative model as an extension of the IVE model that includes the social immersive perspective and resulting socio-empathical factors characterising the social dimension of the resulting user experience.

There are different forms of social interaction but vocal interaction is the one that requires 
the highest level of participants' attention. While vocal interactions support the feeling of social presence, it makes easier the ability to reach a shared mutual understanding for each participant [41], [50]. According to Eynard, a participant of an experiment declared during the focus group debriefing [41]: "I was staying as close as possible to my team partner in the virtual environment as if I was willing to remain audible while I perfectly new that we were in fact talking to each other through the use of a headset". This empirical study demonstrated that vocal interaction tends to decrease the feeling of being present, while at the same time it increases the feeling of co-presence.

For sure, all participants do not necessarily need to be perceptually immersed (sensorymotoric immersion) because of the possibility given to some of the participants to interact vocally with the one that is fully immersed and can interact with the virtual environment. It means that while participants are socially immersed and at least one of them is perceptually immersed then they can interact vocally with the immersed one for inducing actions on affordances. For example, one participant wears a HMD and all the other participants watch him evolving in the virtual environment on a large display while interacting vocally with him. The social immersion allows a group of stakeholders that are not necessarily all fully immersed to efficiently co-create together with a lower effort and cost. This is especially true for people that do not accept immersive technologies, such as people suffering from cyber-sickness (e.g. spatial disorientation).

\subsection{ICE Tree Structure}

Presently, the elaborated ICE structure (Figure 3) is a simple tree highlighting the two sides of the same coin, namely: the cocreation side or Collaborative eXperience (CX) and immersion side or Immersive eXperience (IX). Both include cognitive and social aspects while the IX side owns the perceptual and emotional aspects. They are both implemented in the immersive cocreation platform and in the resulting immersive collaborative experience that appears in the Figure 2 separately in two columns.

All elements appearing in the Figure 3 are inherited from the Table 1 and are intended to lead to the selection of factors for assessing the performance of different ICEs. We don't know yet whether the co-creation and immersion facets' elements or factors are correlated or not. This is to be revealed by the up-coming experiments. It is also expected a refinement and validation of the ICE structure and model based on the results of experiments.

The extension of the Figure 3 is characterised by the decomposition of the RWD element of the IX in three different properties. According to Jennett [38], RWD measures losing track of time, lack of awareness of surroundings (e.g. distracters) and mental transportation (e.g. a person feels completely absorbed in an activity, hence, does not feel any longer aware of being in the real world). In this ICE structure, the three properties are formalised as "timeless" for the lack of time track, "attention-less" for the lack of awareness of external surroundings events and "respondless" for the lack of being responsive to external solicitations. Apparently, these three RWD properties depend on the extend to which one or more persons are absorbed by a common task.

\section{METHODOLOGY 4.1 Design an exploratory experiment} Our goal is to explore what could be the most appropriate ICE model. For that, we created a tentative ICE model (see Figure 2), based on a previously described IVE model and its structure with a root, experience type (or facet), element and property levels (see Figure 3). We design an exploratory experiment based on the use of mixed methods [51], involving active participants that used our low-cost immersive technologies and then responded to a specific bipolar survey questionnaire (18 questions in Appendix 9.1). 
In this experiment, the dependent variable is the collaborative experience that is measured by 8 properties while the real-world dissociation of the IX is evaluated by 1 (timeless) out of 3 properties. The independent variable is the immersive technology with three technology platforms: Computers Screen (2 workstations) platform, one Immersive Bubble platform, and one Multitouch Table platform (Figure 1). The platform d (Figure 1) will be included in the next experiment.

Our hypothesis is that these immersive technologies generate different levels of individual and collective immersive experiences. Actually, in this study we did not evaluate if participants share the same level of immersion. We rather focus on the collaborative performance of these three different immersive environments. Thus, this first experiment mainly focuses on the "Collaborative" experience. For each aspect of the four "collaboration" elements we created two bipolar questions by property, except for "Group Dynamics" property for which we made four complementary questions. Interviewees can select only one answer chosen between two antonyms (e.g. easily vs. hardly) for most questions.

\subsection{Case Study Design}

4.2.1 Smart city context involving complementary stakeholders

Our experiment is based on a specific case study about road accidents occurring in the city. This case study involved several tasks around smart city topic. In particular, we created an experiment around a new tool to make more visual open data on road accidents entitled "Nancy'curity", as a concatenation of the city name and security. Four engineer students in computer science designed this original web-app during a "big data smart city" workshop conducted from January to March 2017. Students used HTML, JavaScript, CSS, Qjis software and GoogleMaps web interface. Using open data from French Government, this open source based app allows locating on a city map all the road accidents that occurred the previous five years in the area of Nancy Metropolis. Furthermore, this app can show the restricted speed areas: dark-blue line on Figure 4 shows speed limit $(30 \mathrm{~km} / \mathrm{h})$; green, light-blue, and red lines show respectively the distances of $50 \mathrm{~m}, 100 \mathrm{~m}$, and $200 \mathrm{~m}$ around the restricted speed areas (Figure 4).

\subsubsection{Experimental collaborative situations}

This case study consists to ask volunteers to take on the role of municipality technicians working with other stakeholders. As local technicians they have to make a road safety diagnosis from two case studies designed by the research team. The two case studies give the same kind of information: the place, the name of the road, the date and the time of one accident, and a screenshot of the local area where took place the studied accident (Figure 5). The two screenshots were taken from the "Nancy'curity" app; finally, the only difference between the two case studies is their place in the same city.

The team exercise is composed of three tasks to be carried out in a global time of $15 \mathrm{~min}$. The participants must find the road accident case's place on the dynamic map generated by "Nancy'curity" app. Then teams had to analyse and describe the events leading up to accidents (urban environments, involved persons, weather conditions, etc.) and the potential causes. With this shared diagnosis, each team had to imagine and design how to improve both the urban environment and road safety. During the exercise each team can navigate in the web app (Figures 4,5 \& 6) and fill in a shared paper form with their suggestions.

\subsubsection{Participants}

Twelve students in psychology constituted our panel of participants: 7 female and 5 male who already know each other. This experiment was a part of their training on exploratory approach and research methods. Furthermore, we selected this group of students due to their potential interest for these Information Technology (IT) tools. Indeed, as future professionals of spatial 
cognition they should be able to use such tools. Immersive technologies and the LF2L research platform were new for all the participants. We divided our panel of 12 participants in four-teams of 3 participants. All teams used our immersive technologies in parallel and were involved in the similar collaborative situations in order to complete the full cycle (Immersive Bubble, Multitouch Table, Computer Screen) as described above.

After a first iteration, groups filled in the exploratory questionnaire and moved towards another immersive technology and worked on the other case study (Table 2). At the end of the $2^{\text {nd }}$ immersion they filled in the exploratory questionnaire.

\section{RESULTS}

This experiment took place for about two hours and included the presentation of the research study and the indications for the experiment; the two iterations followed by individual survey; and a group discussion. Furthermore, three researchers observed and advised the participants. In the next subsections, we synthesize our collected data.

\subsection{Findings from the questionnaire}

The 12 participants filled in one form after each case exercise of the whole study. Thus we collected 24 questionnaires. We analysed the results below.

\subsubsection{Sense Making (SMa) and Trust Building (TB)}

During the exercises people shared trust, mutual confidence and understanding. Indeed, all the participants answered "easily" at SMaR.1, SMaR.2 and SMaCA.1, SMaCA.2 except one respondent who felt his/her partners were not able to explain the case using the Multitouch Table.

The participants also said that they trusted their teammates (TBC.1) and question TBC.2 demonstrates that their teammates trusted them. Furthermore, the participants supported each other, except 2 participants, 1 for the two iterations, who said they were not supportive for their partners with the Multitouch Table platform (TBIT.1, TBIT.2).

Thus, "Relevance" (SMaR), "Context Awareness" (SMaCA), "Interpersonal Ties" (TBIT), and "Confidence" (TBC) seem at least maintained, even properly supported by our technology.

\subsubsection{Shared Meanings (SMe) and Mutual Understanding (MU)}

As shown in Figure 7, the results for "Knowledge Sharing" (SMeKS), Knowledge Creation (SMeKC) are less consistent that Sense making and Trust building. One participant during the $1^{\text {st }}$ iteration said that outcomes from Multitouch Table are from individual work, but for the others the work is collective (SMeKS.1). Nevertheless, Question SMeKS.2 shows that for 7 situations, participants estimate their individual contribution as weak. Specifically, 5 in 7 situations are linked to Immersive Bubble or Multitouch Table. In our experimentation, Computer Screen appears as generating more collective contribution.

It also reveals that 9 out of 24 participants' feedbacks show that technologies generate new knowledge for users; then 15 out of 24 participants' feedbacks show that they learnt from their teammates. This is a significant indication for "Shared Meaning" that interactions around immersive technologies generate knowledge exchange inside the group of participants.

Then, we study "Group Dynamics" (MUGD) through four questions. Overall, outcomes show that participants controlled the situation, except when using the Immersive Bubble platform. However, with this platform, 4 out of 6 participants' feedbacks said that the situation was out of their control, in particular during the $2^{\text {nd }}$ iteration: indeed all the answers are negative (MUGD.1). In parallel, a great majority of participant, 22 out of 24 participants said that their teammates controlled the situation (MUGD.2). Moreover, during the $1^{\text {st }}$ iteration the participants estimated that they controlled the 
situation in an equivalent manner with their teammates. Nevertheless, during the $2^{\text {nd }}$ iteration two participants within the Immersive Bubble platform and two participants with Multitouch Table platform indicate that their teammates took a better control (MUGD.3). Finally, in some case with the Immersive Bubble platform, some students think that the others better controlled the situation, but the questionnaire reveals that the others admitted not control. Finally, the last question dedicated to the "Group Dynamics" aspect (MUGD.4) shows that for all the participants the communication with their teammates was efficient.

Regardless our experimental immersive technologies, participants used "Collective Intelligence" (MUCI). Indeed, all participants in all situations shared the feeling that they collectively solved the task of the case under scrutiny (MUCI.1). However, during the two iterations with the Multitouch Table platform, one participant per group thought that she/he did not collaborate with its partners (MUCI.2). We can underline that this two participants are the same who considered being non-supportive with their partners (TBIT.2) and not so contributing to the group productions (SMeKS.2).

Outcomes of our questionnaire show that participants demonstrate goodwill to each other. During this short experiment, participants, who were lost or out of control with the technology or the case under scrutiny, trusted and relied on their group. "Mutual Understanding" can thus be understood as a "spirit of solidarity" against a new challenge. In other word, if one participant does not understand the situation or the technology, then her/his colleagues are in a different or identical situation, but they act together as a team in sharing their individual knowledge and understanding in order to reach a common understanding. Further studies could be launched for evaluating more precisely the role of Immersive Collaborative Environments in the generation of this kind of solidarity spirit.

\subsubsection{Real-World Dissociation}

Finally, the e.1.q1 question about RWD reveals different feelings: for two participants the exercises had passed slowly (Immersive Bubble then Computer); after the $2^{\text {nd }}$ iteration, three more participants had the same feeling. These three participants were in the same group operating on the Immersive Bubble platform. Thus, with 5 out of 6 participants, the Immersive Bubble platform had the worst level of RWD. According to our observations, it may be attributed to the latency generated by the technology. User has to move arms in front of a motion sensor and these gestures generate commands to Google Street Map or View (GSM/V), giving the illusion of motion along a street. Furthermore, one member of the group played with the sensor while the other members were seating inside our large inflatable bubble. This asymmetry, between one active and 2 passive participants, seems resulting in boredom for passive participants.

\subsection{Qualitative outcomes}

\subsubsection{Findings from the group discussion}

At the end of the two iterations, we organized a group discussion with all the participants based on specific questions (Appendix 9.2).

All teams really appreciated the possibility to adopt GSV besides the maps with all the technologies. This function helps to identify accidents' places; generate discussions; share knowledge and make hypothesis on the incident causes.

Participants' feedbacks also underline that several technical limits became apparent during the experimentation: (1) the tools and interface needs to be carefully checked (e.g. for one group, pinpoints didn't appear on the bird view, needing to re-launch the software); (2) strengthened or used in a more appropriate way because for example participants said that it is very difficult to read the streets' names on the bubble surface, hence, they recommended to project on a smoother and flatter material.

In fact, a maximum of five persons can be accommodated inside the bubble. In all case, 
only one person stays standing, using its arms to orient inside GSM/V and virtually walk along the street. The other persons are just seating on either side of the controller. These different positions seem inefficient due the passivity of seating participants. Only the participant standing at the centre of the bubble can see all the large projection, while the others are not so engaged and feel frustrated. After the experiment, participants suggested that a computer mouse should replace the motion sensing input device. In other word, they were interested by the size of the projection because a large display generates a higher feeling of immersion. However, the "shared" virtual walk did not convince them.

Finally, participants were more collaborating for understanding and learning how to use appropriately the Immersive Bubble platform than solving the incident case under scrutiny. Teams felt that they were more talking about the platform than they talked about the incident case due to the inconvenience of the immersive bubble technology. It became obvious when comparing with the participants' feedback about the Multitouch Table platform that was much more engaging all of them. This platform appears as providing a better feeling of immersion due to the size of the display and that all participants were able to see the same elements of the incident case. Finally, the panel of participants questioned the real impact on teams' production in comparison to the traditional Computer Screen. Nevertheless, the participants really appreciated to draw and co-create using virtual 3D objects with the experimental multitouch interface. "This is an asset that we can draw," said one student. Indeed, according the Multitouch Table potential, we developed an original application including "Nancy'curity" and offering advanced navigation as well as interaction capabilities. Using a digital experience creation platform, we built an interactive experience allowing selecting street-views of the accident's place and customize this view drawing with fingers or adding 3D objects (cars, trucks, houses, buildings, trees, etc.) Every team has used this digital tool to illustrate or reproduce the accident and co-created new elements for improving road safety (Figure 8).

The group discussion also developed beyond immersive technology. For example, participants suggested investigating how the possession of a driver's license (i.e. a knowledge of the driving rules and driving experience) could impact the way of solving a specific incident case. Furthermore, they asked the same question about the knowledge of the place like how a real experience of the road environment helps to understand and analyse an incident case.

\subsubsection{Outstanding issues}

We assume that the exploratory aspect of our questionnaire and our experiment through iterations between the elements generated new knowledge and specific questions that we explored in order to strengthen ICE evaluation model and metrics.

How time and the technical expertise influence the degree of collaboration? Can we observe more collaboration or more tasks distribution through the time? Can we improve our exercise and put the collaboration as the key to the success? How to design a more complex situation in which the more one collaborates, the more one succeeds?

How can we enrich our metrics? Which indicators can be used to indirectly measure the ICE impact on collaboration? E.g. curiosity as parameter of efficient collaboration: Is group curiosity increasing, as indicated by a larger amount of accurate data? In this case we could compare the qualitative group productions (text and picture). In our case, these data are not relevant due to the low level of complexity of our case study.

As evaluation and recognition of weighting team results, Rigby et al. [52] suggest "shifting metrics from output and utilization rates (how busy people are) to business 
outcomes and team happiness (how valuable and engaged people are)."

We also need to experiment our ICE model with a greater diversity of participants, reflecting the multidisciplinary context of organization. This aspect will also contribute to evaluate the ICE model and structure.

According to the group discussion and our observations, one aspect of the experimental protocol could be easily improved. It seems for this kind of experiment that it is relevant to give some advises before starting with the multitouch interface and the other immersive technologies; and to let the participants to do a dry run of the new equipment for few minutes.

\section{CONCLUSION AND PERSPECTIVES}

In a first step, we have created an ICE model, its structure and metrics based on our own previous work and through a specific literature review for identifying the most relevant elements and selecting the most appropriate ones for the context of immersive collaborative environments. In a second step, we have designed an exploratory instrument and experiment conducted on LF2L platform. Thus, this study highlights the interdependency and complementarity between quantitative and qualitative instruments leading to apply a mixed-methods approach.

As a conclusion of this empirical study, though it is still on-going work, we have identified a fourth facet to the construct of immersion that is "social immersion". However, the social aspect was already perceived in the previous IVE model through the socio-emotional and socio-cognitive immersion facets. These two facets represented the potential group behaviour and collective intelligence that could already be observed in multi-user immersive games.

Furthermore, for future studies and experiments, in particular with SMEs and professionals, we have to take into account the maturity of the ecosystem (technology, usages, business, internal organization, partnership, etc.) Indeed, the development of an experimental metrology based on mixedmethods for the ICE performance depends on several interconnected dimensions. Moreover, this exploratory research focuses on short term. We only evaluated the direct impact of ICE on immediate collaboration. We can talk about direct profit for users. This is the initial value generated by ICE. It seems other values could be identified and integrated in our metrology as the "strategic value", derived from the connections that participants establish with one another and from further collaborations; or the "Exit value" defined by learnt knowledge, components, or solutions, tapped by participants in the future. These values are adapted from [2].

Finally, as future work, we will continue to reconcile the immersive and collaborative experience. The outcomes of the up-coming experiments will allow refining and eventually validating totally or partially our proposed ICE model, structure and metrics.

\section{ACKNOWLEDGMENTS}

This work was carried out in the context of collaboration between ERPI research team and Arts \& Métiers ParisTech LAMPA P\&I research team through a research project dedicated to several experiments on immersive environments for co-creation. Authors wish to acknowledge their gratitude and appreciation to all colleagues for their support and students from Université de Lorraine that contributed to this study.

\section{REFERENCES}

[1]. B. Marche, V. Boly, L. Morel, F. Mayer, and R. Ortt, "Innovative product's supply chain: how to model it.," in 2017 International Conference on Engineering, Technology and Innovation (ICE/ITMC), 2017, pp. 190-201.

[2]. N. Furr, K. O'Keeffe, and J. H. Dyer, "Managing Multiparty Innovation," Harward Buisness Review, no. November, pp. 76-83, 2016. 
[3]. L. Dupont, C. Guidat, L. Morel, and N. Skiba, "The role of mock-ups in the anticipation of the user experience within a living lab: An empirical study," in 2015 IEEE International Conference on Engineering, Technology and Innovation/ International Technology Management Conference (ICE/ITMC), 2015, pp. 1-8.

[4]. L. Dupont, M. Pallot, and L. Morel, "Exploring the Appropriateness of Different Immersive Environments in the Context of an Innovation Process for Smart Cities.," in 22nd ICE/IEEE International Technology Management Conference, 2016.

[5]. M. Pallot, R. Eynard, B. Poussard, O. Christmann, and S. Richir, "Augmented sport: exploring collective user experience.," in Proceedings of the Virtual Reality International Conference on Laval Virtual - VRIC '13, 2013, p. 1.

[6]. V. Ramaswamy and F. J. Gouillart, The Power of Co-Creation: Build it with them to Boost Growth, Productivity, and Profits. New York: Free Press., 2010.

[7]. M. Pallot, Collaborative Distance: Investigating Distance Factors Affecting Collaboration Performance. LAP LAMBERT Academic Publishing, 2012.

[8]. M. Pallot, C. Le Marc, S. Richir, C. Schmidt, and J.-P. Mathieu, "Innovation Gaming: An Immersive Experience Environment Enabling Co-creation," in Handbook of Research on Serious Games as Educational, Business and Research Tools, M. Cruz-Cunha, Ed. Hershey, PA: IGI Global, 2012, pp. 124.

[9]. J. N. Bailenson, J. Blascovich, A. C. Beall, and J. M. Loomis, "Interpersonal Distance in Immersive Virtual Environments," Personal. Soc. Psychol. Bull., vol. 29, no. 7, pp. 819-833, Jul. 2003.

[10].I. Rihova, D. Buhalis, M. Moital, and M. Beth Gouthro, "Social layers of customer-to-customer value co-creation," J. Serv. Manag., vol. 24, no. 5, pp. 553566, Oct. 2013.
[11].L. Freina and M. Ott, "A literature review on immersive virtual reality in education: State of the art and perspectives," in Proceedings of eLearning and Software for Education (eLSE)(Bucharest, Romania, April 2324, 2015), 2015, p. 8.

[12].E. Brown and P. Cairns, "A grounded investigation of game immersion," in Extended abstracts of the 2004 conference on Human factors and computing systems - CHI '04, 2004, p. 1297.

[13].A. I. Nordin, A. Denisova, and P. Cairns, "Too Many Questionnaires: Measuring Player Experience Whilst Playing Digital Games," in Seventh York Doctoral Symposium on Computer Science \& Electronics, 2014, pp. 69-75.

[14].A. I. Nordin, J. Ali, A. Animashaun, J. Asch, J. Adams, and P. Cairns, "Attention, time perception and immersion in games," in CHI ' 13 Extended Abstracts on Human Factors in Computing Systems on - CHI EA '13, 2013, pp. 1089-1094.

[15].J. H. Brockmyer, C. M. Fox, K. A. Curtiss, E. McBroom, K. M. Burkhart, and J. N. Pidruzny, "The development of the Game Engagement Questionnaire: A measure of engagement in video gameplaying," J. Exp. Soc. Psychol., vol. 45, no. 4, pp. 624-634, Jul. 2009.

[16].C. Jennett, A. L. Cox, P. Cairns, S. Dhoparee, A. Epps, T. Tijs, and A. Walton, "Measuring and defining the experience of immersion in games," Int. J. Hum. Comput. Stud., vol. 66, no. 9, pp. 641-661, 2008.

[17].A. Cox, P. Cairns, P. Shah, and M. Carroll, "Not Doing But Thinking: The Role of Challenge in the Gaming Experience," in CHI'2012 ACM annual conference on Human Factors in Computing Systems, 2012, pp. 79-88.

[18].M. Thompson, A. Nordin, and P. Cairns, "Effect of touch-screen size on game immersion," in Proceedings of the 26th Annual BCS HCI 2012 People \& Computers, 2012, pp. 280-285. 
[19].T. Sanders and P. Cairns, "Time perception, immersion and music in videogames," in Proceedings of the 24th $B C S$ Interaction Specialist Group Conference, 2010, pp. 160-167.

[20].P. Cairns, "A Commentary on Short Questionnaires for Assessing Usability," Interact. Comput., vol. 25, no. 4, pp. 312-316, Jul. 2013.

[21].Y. A. W. De Kort, W. Ijsselsteijn, and K. Poels, "Digital Games as Social Presence Technology : Development of the Social Presence in Gaming Questionnaire ( SPGQ )," in Proceedings of PRESENCE 2007, The 10th International Workshop on Presence, 2007, pp. 195-203.

[22].M. Pallot and S. Richir, "Laval Virtual Vision 2025 : Blurring the lines between digital and physical worlds," in Proc. 11th Intl Conf. Disability, Virtual Reality \& Associated Technologies, 2016, pp. 19.

[23].L. Dupont, L. Morel, and P. Lhoste, "Le Lorraine Fab Living Lab: la 4ème dimension de l'innovation," in Actes des sessions $d u$ colloque Science \& You, France, 2015, pp. 230-235.

[24].L. Dupont, V. Gholipour, L. Morel, J.-C. Bignon, and C. Guidat, "From Urban Concept to Urban Engineering: The Contribution of Distributed Collaborative Design to the Management of Urban Projects," J. Urban Des., vol. 17, no. 2, pp. 255-277, May 2012.

[25].C. Roth and H. Koenitz, "Evaluating the User Experience of Interactive Digital Narrative," in Proceedings of the 1st International Workshop on Multimedia Alternate Realities - AltMM '16, 2016, pp. 31-36.

[26].D. Bombari, M. Schmid Mast, E. Canadas, and M. Bachmann, "Studying social interactions through immersive virtual environment technology: virtues, pitfalls, and future challenges," Front. Psychol., vol. 6, Jun. 2015.

[27].F. Biocca, J. Burgoon, C. Harms, and M. Stoner, "Criteria for a theory and measure of social presence," in 4th Annual International Workshop on
Presence, 2001.

[28].M. Cavazza, R. Aylett, K. Dautenhahn, C. Fencott, and F. Charles, "Interactive storytelling in virtual environments: building the "Holodeck," in Proceedings of VSMM 2000, 2000.

[29].R. Aylett, "Emergent Narrative, Social Immersion and 'Storification," in $1 s t$ International Workshop on Narrative and Interactive Learning Environments (NILE 2000), 2000, pp. 35-45.

[30].D. Pietschmann, B. Liebold, and G. Valtin, "The MMORPG designer's journey: casualization and its consequences for social interactions.," in New Perspectives on the Social Aspects of Digital Gaming: multiplayer 2, T. Quandt and R. Kowert, Eds. New York: Routledge, Taylor \& Francis Group, 2017.

[31].S. Louchart, R. Aylett, L. Hall, S. Woods, and A. Paiva, "FearNot! Developing Social Immersion in the VICTEC and ECIRCUS Projects," in Ludovia 2006 Université du multimédia ludo-éducatif et pédagogique, 2006.

[32].G. Bente, S. Rüggenberg, and N. Krämer, "Social Presence and Interpersonal Trust in Avatar-Based, Collaborative Net-Communications," in PRESENCE 2004: Proceedings of the 7th Annual International Workshop on Presence, 2004, pp. 54-61.

[33].C. L. Hoyt, J. Blascovich, and K. R. Swinth, "Social Inhibition in Immersive Virtual Environments," in Presence: Teleoperators and Virtual Environments, 2003, vol. 12, no. 2, pp. 183-195.

[34].M. Pallot, L. Dupont, O. Christmann, S. Richir, B. Vincent, and L. Morel, "ICE Breaking: Disentangling Factors Affecting the Performance of Immersive Co-creation Environments," in VRIC '17 Proceedings of the Virtual Reality International Conference, 2017.

[35].A. S. Lu, T. Baranowski, D. Thompson, and R. Buday, "Story Immersion of Videogames for Youth Health Promotion: A Review of Literature," Games Health J., vol. 1, no. 3, pp. 199- 
204, 2012.

[36].Keith Stuart, "What do we mean when we call a game immersive?," The Guardian, 11-Aug-2010. [Online]. Available:

http://www.theguardian.com/technology/ gamesblog/2010/aug/10/games-scienceof-immersion. [Accessed: 10-Mar-2017].

[37].D. Gábana Arellano, L. Tokarchuk, and H. Gunes, "Measuring affective, physiological and behavioural differences in solo, competitive and collaborative games," in 8 th International Conference on Intelligent Technologies for Interactive Entertainment - Intertain (June, 28-30), 2016, pp. 1-10.

[38].C. Roth, "Experiencing Interactive Storytelling," Vrije University, Amsterdam, 2015.

[39].C. Jennett, A. L. Cox, and P. Cairns, "Investigating computer game immersion and the component real world dissociation," in Proceedings of the 27th international conference extended abstracts on Human factors in computing systems - CHI EA '09, 2009, p. 3407.

[40].C. Zhang, A. S. Hoel, and A. Perkis, "Quality of Immersive Experience in Storytelling: A Framework," in Eighth International Workshop on Quality of Multimedia Experience QoMEX 2016, 2016, pp. 1-2.

[41].R. Eynard, M. Pallot, O. Christmann, and S. Richir, "Impact of Verbal Communication on User Experience in 3D Immersive Virtual Environments," in IProceedings of the International Conference on Engineering, Technology and Innovation (ICE), ICE'2015, 2015.

[42].M. Nakevska, A. van der Sanden, M. Funk, J. $\mathrm{Hu}$, and $\mathrm{M}$. Rauterberg, "Interactive Storytelling in a Mixed Reality Environment: The Effects of Interactivity on User Experiences," Entertain. Comput. 2014, pp. 52-59, 2014.

[43].G. Calleja, In-Game: From Immersion to Incorporation. The MIT Press; 1 edition
(May 13, 2011), 2011.

[44].P. Gestwicki and R. Morris, "Social Studies Education Game Development as an Undergraduate Immersive Learning Experience," in Handbook of Research on Serious Games as Educational, Business and Research Tools, IGI Global, 2012, pp. 838-858.

[45].P. N. Mustaro and R. L. Mendonça, "Immersion, Narrative, and Replayability as the Motivational and Attractiveness Factors in Serious Games," in Handbook of Research on Serious Games as Educational, Business and Research Tools, IGI Global, 2012, pp. 991-1008.

[46].S. Schnall, C. Hedge, and R. Weaver, "The Immersive Virtual Environment of the digital fulldome: Considerations of relevant psychological processes," Int. J. Hum. Comput. Stud., vol. 70, no. 8, pp. 561-575, 2012.

[47].C. M. Lorenzo, M. Ángel Sicilia, and S. Sánchez, "Studying the effectiveness of multi-user immersive environments for collaborative evaluation tasks," Comput. Educ., vol. 59, no. 4, pp. 1361-1376, 2012.

[48].F. Ke and P. Carafano, "Collaborative science learning in an immersive flight simulation," Comput. Educ., vol. 103, pp. 114-123, 2016.

[49] .A. Cruz, H. Paredes, B. Fonseca, and L. Morgado, "Can Presence Improve Collaboration in 3D Virtual Worlds?," Procedia Technol., vol. 13, pp. 47-55, 2014.

[50].P. Antoniac, M. Pallot, and P. Pulli, "Virtual and augmented reality supporting group consciousness within collaborative working environments Virtual and Augmented Reality Supporting Group Consciousness within Collaborative Working Environments," in 2006 IEEE International Technology Management Conference (ICE), 2006.

[51].P. Krawczyk, M. Topolewskil, and M. Pallot, "Towards a Reliable and Valid Mixed Methods Instrument in User eXperience Studies.," in 2017 
International Conference on Engineering, Technology and Innovation (ICE/ITMC), 2017, pp. 1497-1506.

[52].D. K. Rigby, J. Sutherland, and H. Takeuchi, "Embracing Agile," Harward Buisness Review, no. May, p. pp.40-48, 2016.

\section{APPENDIX}

\subsection{Questionnaire (originally in French)}

A. Sense Making (SMa):

- Relevance (disambiguation) (SMaR), oSMaR.1 - During the exercise, you understood your teammates: easily; hardly.

oSMaR.2 - Within the group, you would say you were able to be understood: easily; hardly.

- Context Awareness (SMaCA)

oSMaCA.1 You would say that you were able to have your teammates understanding the case study: easily; hardly.

oSMaCA.2 You would say that your teammates were able to explain you the case study: easily; hardly.

B. Trust Building (TB):

- Interpersonal Ties (TBIT)

oTBIT.1 You would say that your teammates were with you: supportive; non-supportive.

oTBIT.2 You would say that you were with your teammates: supportive; nonsupportive.

- Confidence (TBC)

oTBC.1 You would say that your teammates: trusted you; distrusted you.

○TBC. 2 You would say that you: trusted your teammates; distrusted your teammates.

C. Shared Meanings (SMe):

- Knowledge Sharing (SMeKS)

oSMeKS.1 You would say that group productions are outcome from: Individual work; Collective work.

oSMeKS.2 Do you consider your contribution for the group productions as: Strong; Weak.
- Knowledge Creation (KC)

oSMeKC.1 Did you learn anything new thanks to the sharing platform (technology)? Yes; No.

oSMeKC.2 Did you learn anything new from your teammates? Yes; No.

D. Mutual Understanding (MU):

- Group Dynamics (MUGD)

oMUGD.1 You would say that the situation is: Under your control; Out of your control

oMUGD.2 You would say that the situation is: Under the control of your teammates; Out of the control of your teammates.

oMUGD.3 Which stakeholder does control the situation? You; Your teammates; You and your team mates in an equivalent manner.

oMUGD.4 You would say that the communication with your teammates was: Efficient; Inefficient.

- Collective Intelligence (MUCI)

oMUCI.1 For you, the task was solved: Individually; Collectively.

oMUCI.2 Did you collaborate with your teammates? Definitely; Not at all.

Only one question focuses on the Immersive eXperience:

E. Real-world Dissociation (RWD)

oRWD.1 You would say that the exercise has passed: Slowly; Quickly.

\subsection{Focus Group questions}

- What do you think about this experiment?

- Do you have any comment on these platforms?

- Do you feel that you collaborate to solve the case study?

- Do you have suggestions to improve these platforms? The experiments?

- What differences you found between Multitouch table platform and Computer Screen platform? Between Immersive Bubble platform and Computer Screen platform?

- Do you have any comments on the case study? 


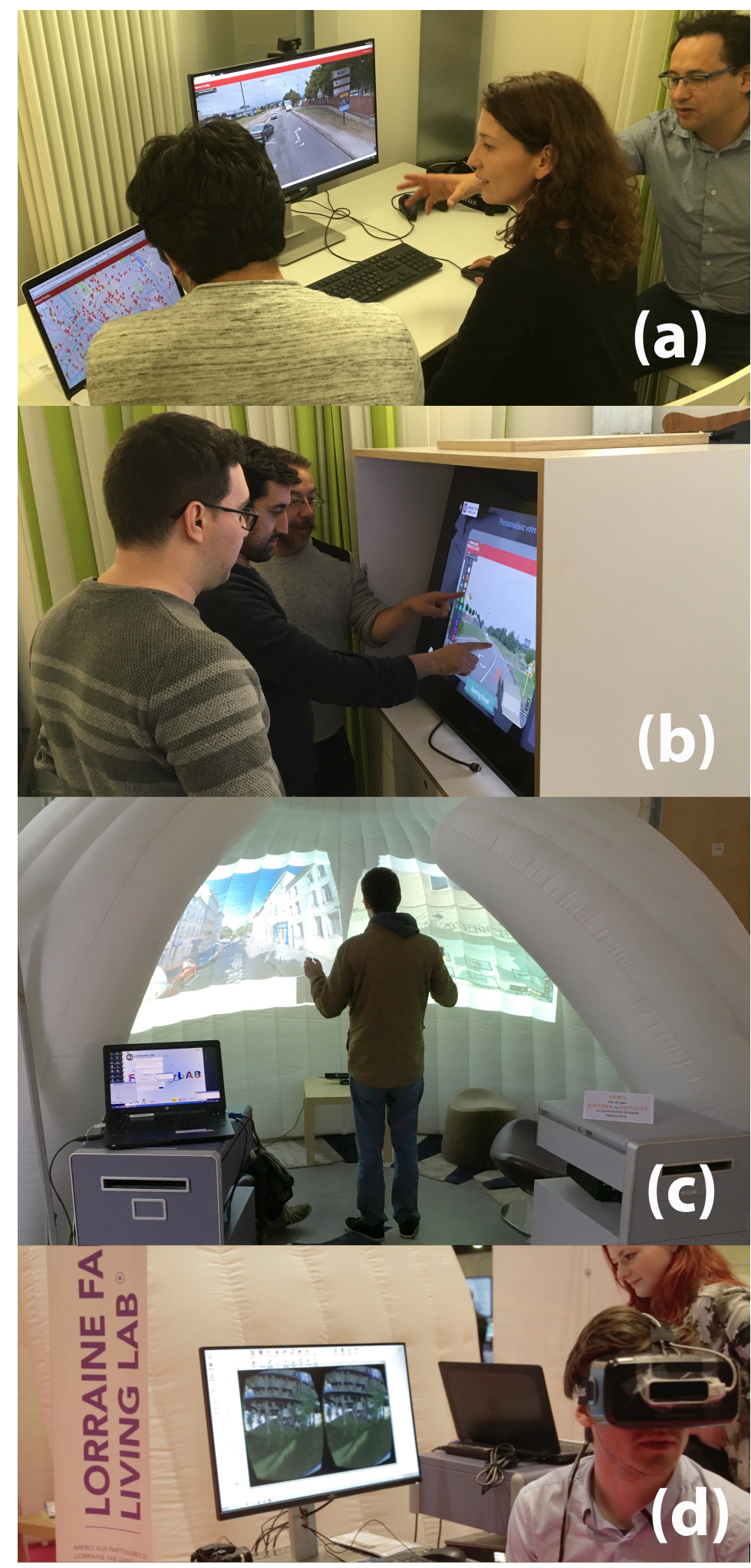

Figure 1. Pictures of LF2L showing the "low-cost" immersive technologies 
Table 1

Previous Work on Immersion \& Collaboration, extended from [34]

\begin{tabular}{|c|c|c|c|}
\hline Seq & Title & Reference & Related Notions \& Potential factors \\
\hline $\mathrm{S} 1$ & $\begin{array}{l}\text { Literature Review: } \\
\text { CAVE \& HMD }\end{array}$ & $\begin{array}{l}\text { Freina \& } \\
\text { Ott }[11]\end{array}$ & $\begin{array}{l}\text { Spatial immersion stimulating interactivity \& motivation; } \\
\text { visual, auditory or kinaesthetic learning style }\end{array}$ \\
\hline $\mathrm{S} 2$ & $\begin{array}{l}\text { Story Immersion of } \\
\text { Videogames for } \\
\text { Youth Health } \\
\text { Promotion: A } \\
\text { Review of Literature }\end{array}$ & $\begin{array}{l}\text { Lu et al. } \\
{[35]}\end{array}$ & $\begin{array}{l}\text { Story immersion; videogame; Narrative transportation; } \\
\text { Story immersion complements behavioural change theories, } \\
\text { including the Theory of Planned Behaviour, Social } \\
\text { Cognitive Theory, and Self-Determination Theory }\end{array}$ \\
\hline $\mathrm{S} 3$ & $\begin{array}{l}\text { What do we mean } \\
\text { when we call a game } \\
\text { 'immersive'? }\end{array}$ & Stuart [36] & $\begin{array}{l}\text { How do you know you are immersed in a game? There are } \\
\text { lots of obvious signifiers (symptoms): time passes } \\
\text { unnoticed; you become unaware of events or people around } \\
\text { you; heart rate quickens in scary parts; you empathize with } \\
\text { the characters }\end{array}$ \\
\hline S4 & $\begin{array}{l}\text { The development of } \\
\text { the game engagement } \\
\text { questionnaire }\end{array}$ & $\begin{array}{l}\text { Brockmyer } \\
\text { and Fox } \\
{[15]}\end{array}$ & $\begin{array}{l}\text { Measurement is the process of developing an equal- interval } \\
\text { linear representation of a quantitative attribute, in common } \\
\text { units, and then subsequently tested for its consistency } \\
\text { (reliability) and validity (interpretive meaning) }\end{array}$ \\
\hline S5 & $\begin{array}{l}\text { Too many } \\
\text { questionnaires: } \\
\text { measuring player } \\
\text { experience whilst } \\
\text { playing digital games }\end{array}$ & $\begin{array}{l}\text { Nordin et } \\
\text { al. [13] }\end{array}$ & $\begin{array}{l}\text { Emotional involvement, Cognitive involvement, Real } \\
\text { World Dissociation (RWD), Challenge, Control, social } \\
\text { interaction, Immersion, Absorption, Flow, Presence, } \\
\text { Psychological involvement, Behavioural engagement, } \\
\text { Usability }\end{array}$ \\
\hline S6 & $\begin{array}{l}\text { Measuring affect, } \\
\text { physiological and } \\
\text { behavioural diff. }\end{array}$ & $\begin{array}{l}\text { Gabana et } \\
\text { al. [37] }\end{array}$ & $\begin{array}{l}\text { Engagement, immersion, frustration, stress, enjoyment, } \\
\text { effort, boredom. }\end{array}$ \\
\hline S7 & $\begin{array}{l}\text { Evaluating the user } \\
\text { experience of } \\
\text { interactive digital } \\
\text { narrative }\end{array}$ & $\begin{array}{l}\text { Roth and } \\
\text { Koenitz } \\
{[25]}\end{array}$ & $\begin{array}{l}\text { Appreciation of interaction (agency), narrative (immersion) } \\
\text { and Combined outcomes (transformation) }\end{array}$ \\
\hline S8 & $\begin{array}{l}\text { Experiencing } \\
\text { interactive } \\
\text { storytelling }\end{array}$ & Roth [38] & $\begin{array}{l}\text { Usability, Flow, Presence, Character believability, Role- } \\
\text { identity, Aesthetic, Curiosity, Suspense, User satisfaction, } \\
\text { Affect, Enjoyment }\end{array}$ \\
\hline S9 & $\begin{array}{l}\text { Measuring and } \\
\text { defining the } \\
\text { experience of } \\
\text { immersion in games }\end{array}$ & $\begin{array}{l}\text { Jennett et } \\
\text { al. [16] }\end{array}$ & $\begin{array}{l}\text { Engaging Experience: Flow, Cognitive Absorption \& } \\
\text { Presence. Immersion is clearly distinct. Emotional } \\
\text { engagement. Eye Tracking for immersion studies }\end{array}$ \\
\hline S10 & $\begin{array}{l}\text { Investigating } \\
\text { computer game }\end{array}$ & Jennett et & Immersive experience: cognitive involvement, RWD, \\
\hline
\end{tabular}




\begin{tabular}{|c|c|c|c|}
\hline Seq & Title & Reference & Related Notions \& Potential factors \\
\hline & $\begin{array}{l}\text { immersion and the } \\
\text { component real } \\
\text { world dissociation }\end{array}$ & al. [39] & $\begin{array}{l}\text { emotional involvement, challenge and control. } \\
\text { RWD measures losing track of time, lack of awareness of } \\
\text { surroundings and mental transportation (e.g. "To what } \\
\text { extent did you feel consciously aware of being in the real } \\
\text { world whilst playing?") }\end{array}$ \\
\hline S11 & $\begin{array}{l}\text { A grounded } \\
\text { investigation of game } \\
\text { immersion }\end{array}$ & $\begin{array}{l}\text { Brown and } \\
\text { Cairns [12] }\end{array}$ & $\begin{array}{l}\text { Engagement, Engrossment, Concentration, Experience, } \\
\text { Total Immersion, Enjoyment. Emotional involvement, } \\
\text { Transportation, Attention, Control and Autonomy }\end{array}$ \\
\hline S12 & $\begin{array}{l}\text { Quality of immersive } \\
\text { experience in } \\
\text { storytelling }\end{array}$ & $\begin{array}{l}\text { Zhang et al. } \\
\text { [40] }\end{array}$ & $\begin{array}{l}\text { Human factors: Physiological, Neuropsychological, } \\
\text { Behavioural; System factors: Haptic Feedback, Graphical } \\
\text { Fidelity, Screen Size, Quality of Service; Design factors: } \\
\text { Narrative, Interactivity, Spatiality, challenge }\end{array}$ \\
\hline S13 & $\begin{array}{l}\text { Augmented sport: } \\
\text { exploring collective } \\
\text { user experience }\end{array}$ & $\begin{array}{l}\text { Pallot et al. } \\
\text { [5] }\end{array}$ & $\begin{array}{l}\text { Experiential engine: Social Presence, Social Emotion, } \\
\text { Emotional Response } \\
\text { Rational engine: Flow, Presence, Acceptance }\end{array}$ \\
\hline S14 & $\begin{array}{l}\text { Impact of vocal } \\
\text { communication on } \\
\text { UX in 3D IVE }\end{array}$ & $\begin{array}{l}\text { Eynard et } \\
\text { al. [41] }\end{array}$ & $\begin{array}{l}\text { Attention, Social Presence, Mutual Comprehension, } \\
\text { Performance, Interdependence, Self Presence, Control, } \\
\text { Concentration, Enjoyment, Translucence }\end{array}$ \\
\hline
\end{tabular}

Exploring the

S15 appropriateness of different immersive env.
Dupont et Immersiveness, Engagement, Interaction, Self Presence, al. [3] Environmental Presence, Social Presence, Collaboration
Interactive storytelling in a

S16 mixed reality env.: the effect of interactivity on UX
Nakevska

et al. [42]
Presence, Agency, Satisfaction, Behavioural measures
Attention, time

S17 perception and immersion in games
Nordin et al. [14]
Immersion, Attention, Time Perception, Dissociation
In game: from

S18 immersion to incorporation
Immersion: six involvement dimensions: Kinaesthetic,

Calleja [43] Spatial, Narrative, Shared, Affective (emotional) and Ludic Involvement.

\section{Social Studies}

Education Game

S19 Development as

Undergraduate

Immersive Learning

Experience
Gestwicki Learning Games, Fun, Flow, Multidisciplinary team, game

et al. [44] design, Immersive Learning Experience 


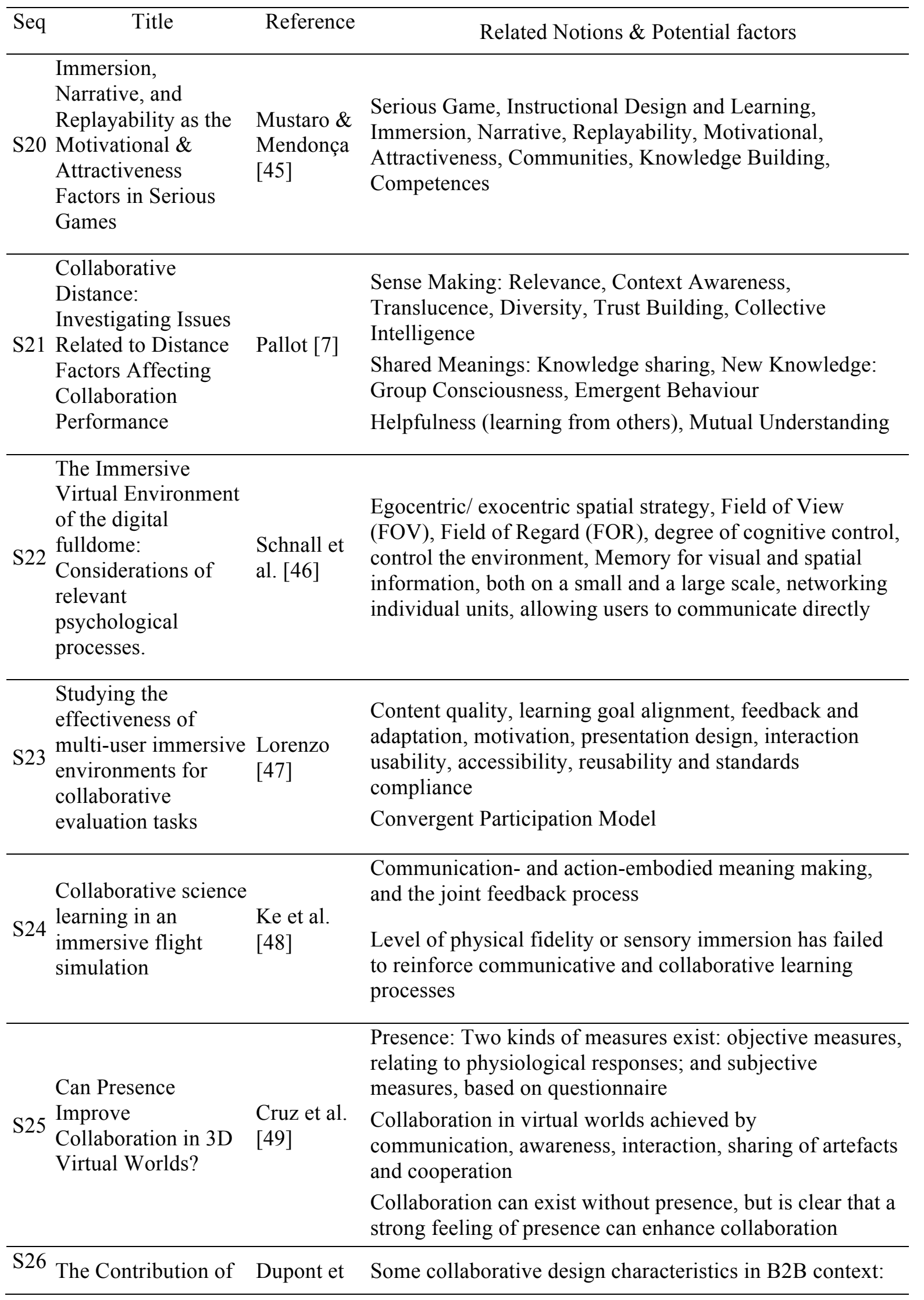




\begin{tabular}{|c|c|c|}
\hline Seq & Reference & Related Notions \& Potential factors \\
\hline & $\begin{array}{l}\text { Distributed al. [24] } \\
\text { Collaborative Design } \\
\text { to the Management } \\
\text { of Urban }\end{array}$ & $\begin{array}{l}\text { Stakeholders develop a solution together; Work together at } \\
\text { the same place; Knowledge intensive process; Media } \\
\text { solution to help conflict resolution and information sharing; } \\
\text { Cognitive synchronization; interdisciplinary; On-going } \\
\text { collective decision; Boundary object and intermediate } \\
\text { artefact; Need specific environments \& Face-to-Face } \\
\text { interactions }\end{array}$ \\
\hline
\end{tabular}




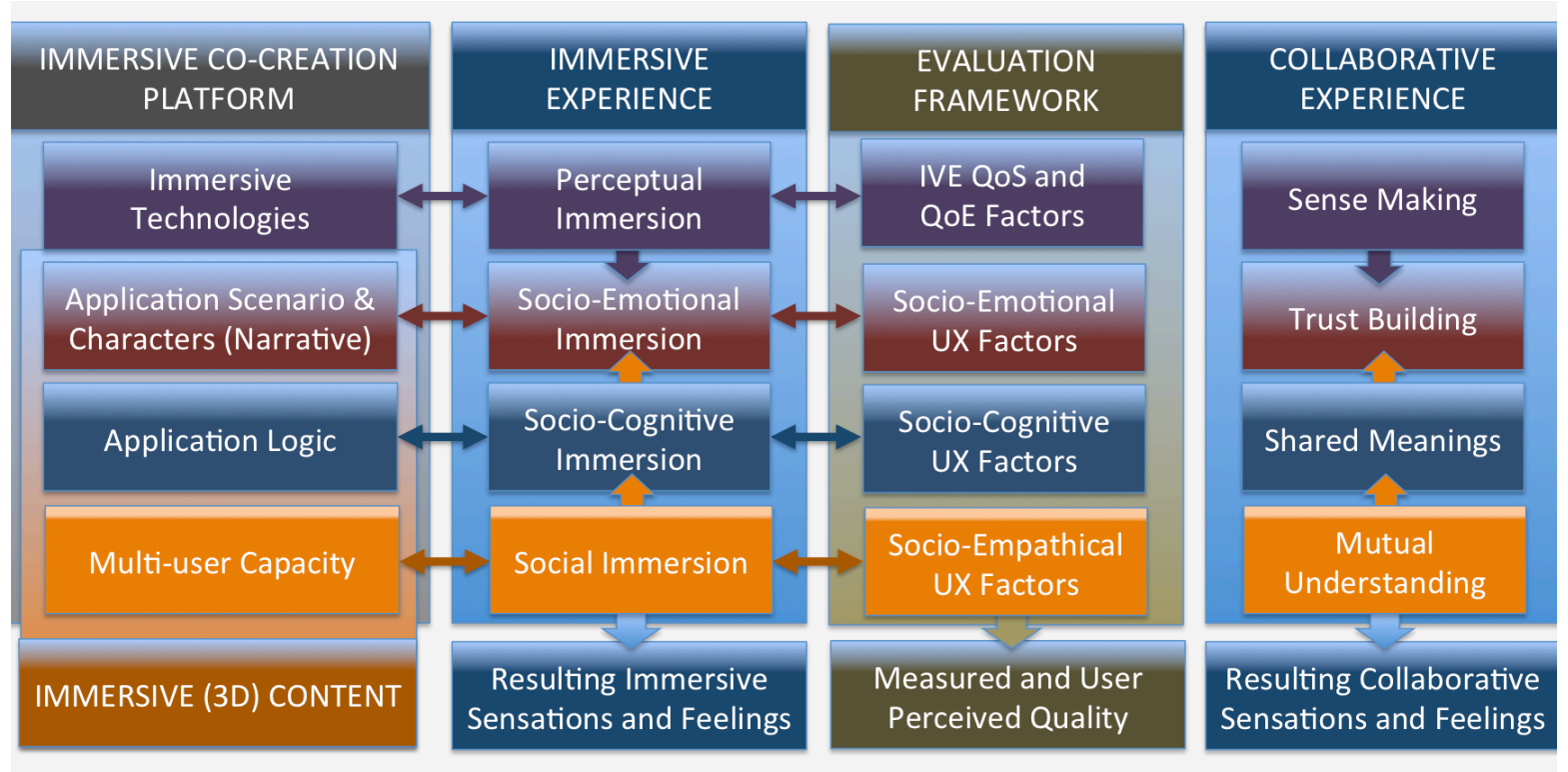

Figure 2. ICE Model [34] based on four different but complementary immersive perspectives, extended from the IVE Model [22] 


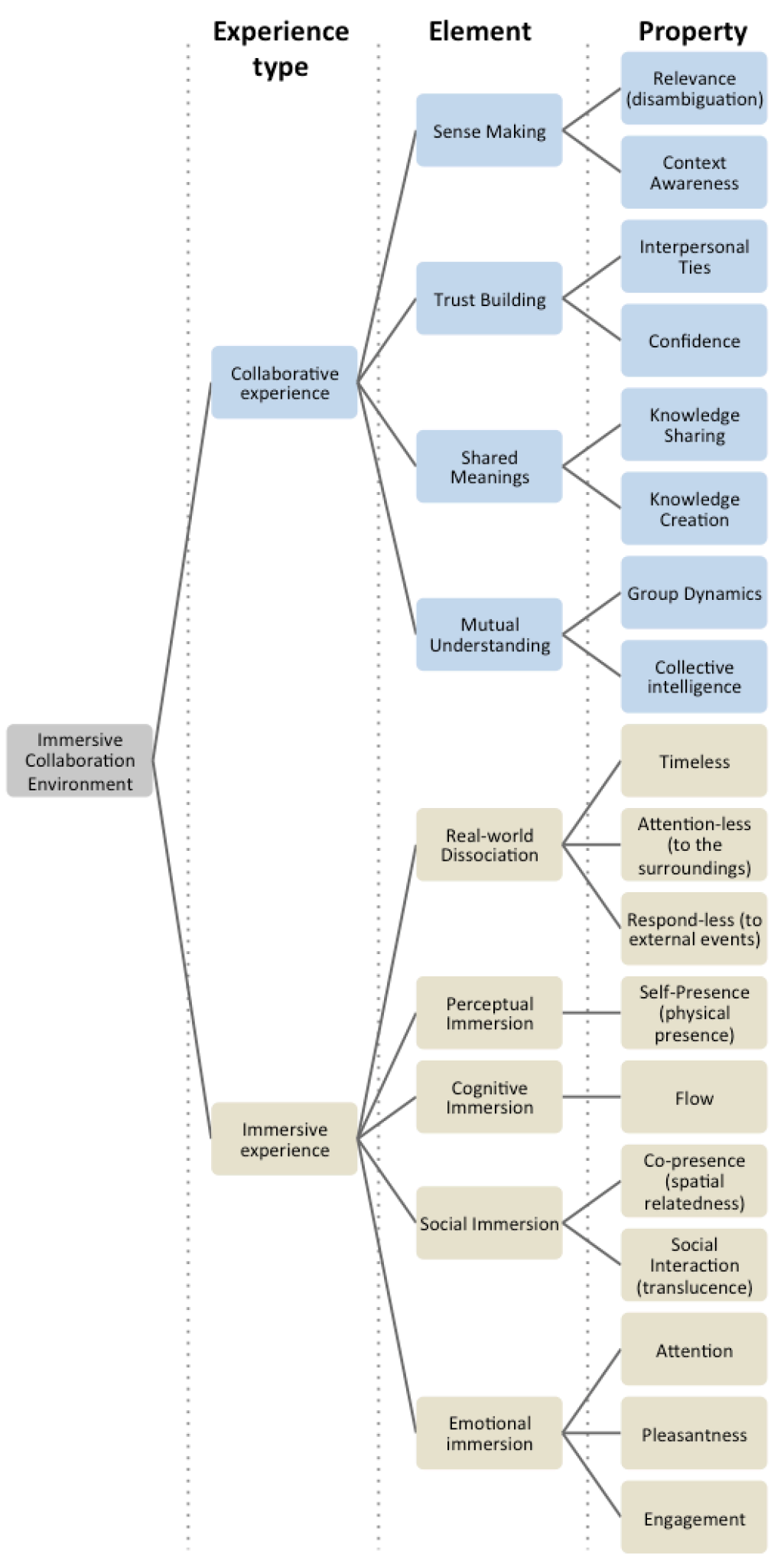

Figure 3. ICE Tree Structure based on synthetized elements of the Table 1 and extended from [34]. 


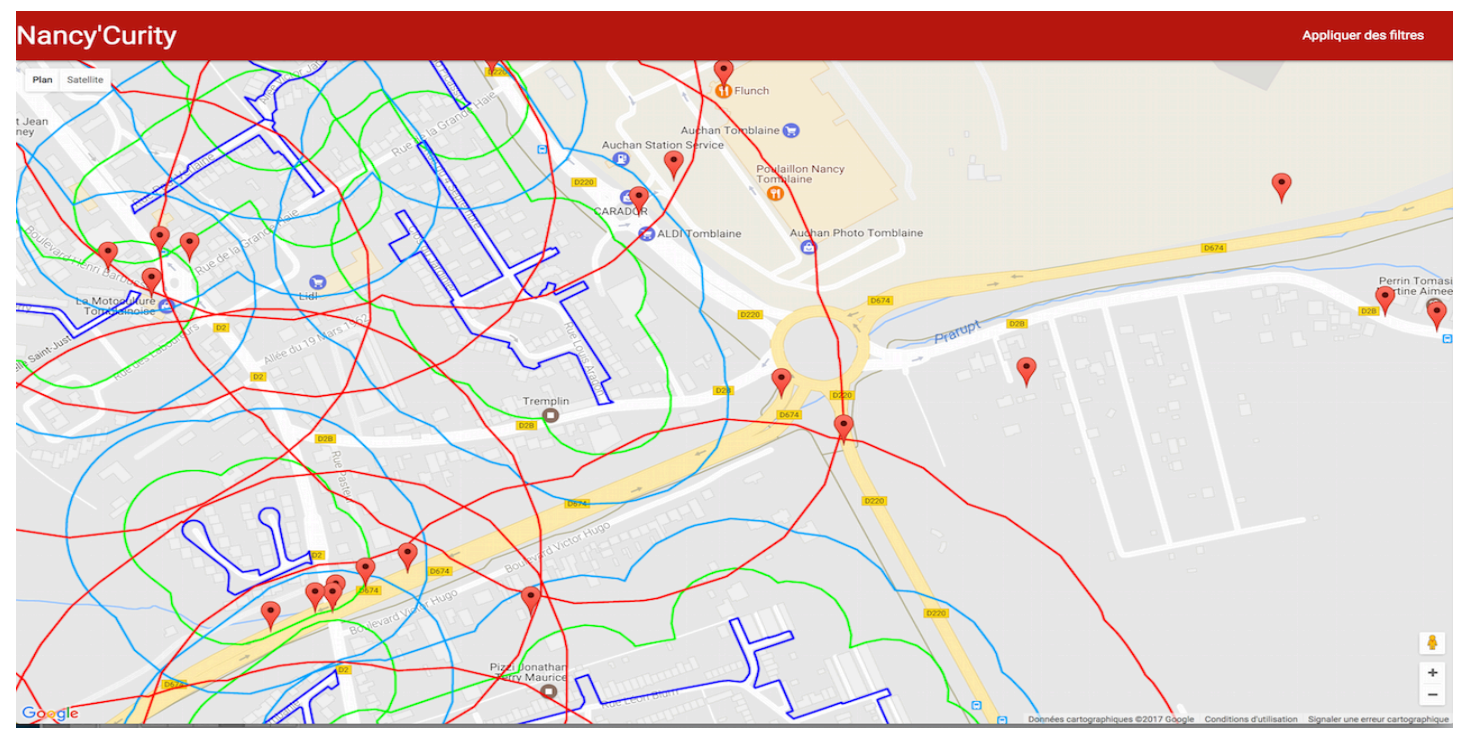

Figure 4. One of the two screenshots provided to the participants. 


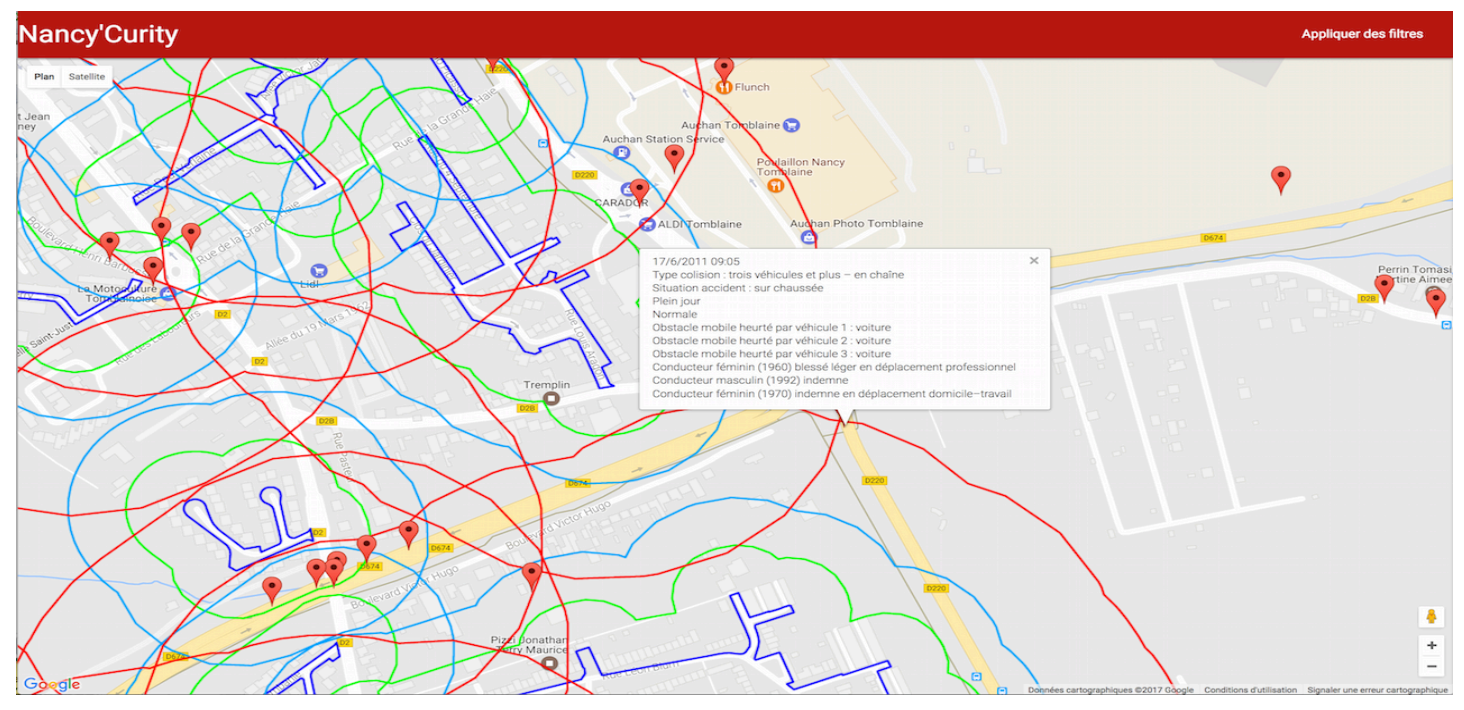

Figure 5. Pinpoints give details on road accidents (conditions, causes, impacts, etc.) 


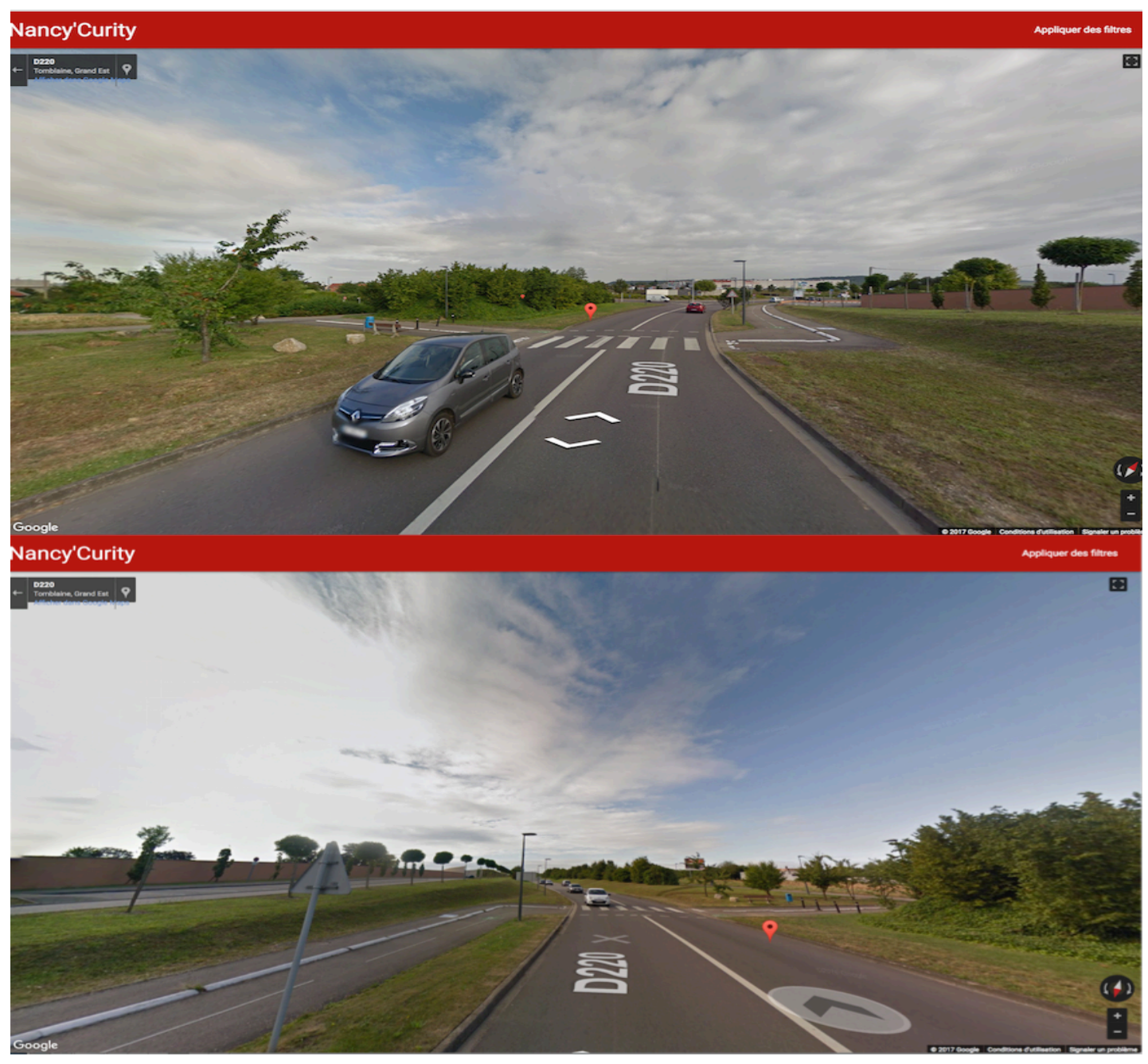

Figure 6. Two views of one case study located by pinpoint 
Table 2

Group repartition by iteration

\begin{tabular}{llcllc}
\hline \multirow{2}{*}{ Group } & \multicolumn{2}{c}{ 1st iteration } & & \multicolumn{2}{c}{$2^{\text {nd }}$ iteration } \\
\cline { 2 - 3 } \cline { 5 - 6 } & $\begin{array}{l}\text { Technology } \\
\text { platform }\end{array}$ & Case study & & $\begin{array}{l}\text { Technology } \\
\text { platform }\end{array}$ & Case study \\
\hline A & Computer Screen & 1 & & Immersive Bubble & 2 \\
B & Computer Screen & 2 & & Multitouch Table & 1 \\
C & Immersive & 1 & & Computer Screen & 2 \\
D & Bubble & Multitouch Table & 2 & Computer Screen & 1 \\
\hline
\end{tabular}


Shared Meanings Knowledge Sharing (SMeKS)

Platforms (Technology) vs. SMeKS.2

Do you consider your contribution for the group productions as

\begin{tabular}{|l|r|c|c|r|r|}
\hline & \multicolumn{1}{|c|}{ Computer } & $\begin{array}{c}\text { Immersive } \\
\text { Bubble }\end{array}$ & $\begin{array}{c}\text { Multitouch } \\
\text { Table }\end{array}$ & \multicolumn{2}{|c|}{ Total } \\
\hline Strong & 10 & 3 & 4 & 17 \\
\hline Weak & 2 & 3 & 2 & 7 \\
\hline Total & 12 & $\mathbf{3}$ & $\mathbf{6}$ & $\mathbf{6}$ & $\mathbf{2 4}$ \\
\hline
\end{tabular}

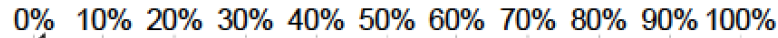

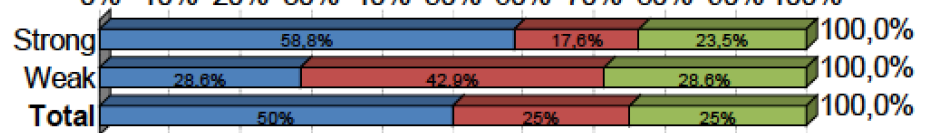

Shared Meanings Knowledge Creation (SMeKC)

Platforms (Technology) vs. SMeKC.1

Did you learn anything new thanks to the sharing platform (technology)?

\begin{tabular}{|l|r|c||cr|r|}
\hline & \multicolumn{1}{|c|}{ Computer } & $\begin{array}{c}\text { Immersive } \\
\text { Bubble }\end{array}$ & $\begin{array}{c}\text { Multitouch } \\
\text { Table }\end{array}$ & \multicolumn{2}{|c|}{ Total } \\
\hline Yes & $\mathbf{2}$ & $\mathbf{3}$ & $\mathbf{4}$ & $\mathbf{9}$ \\
\hline No & 10 & $\mathbf{3}$ & $\mathbf{2}$ & $\mathbf{1 5}$ \\
\hline Total & $\mathbf{1 2}$ & $\mathbf{6}$ & $\mathbf{6}$ & $\mathbf{2 4}$ \\
\hline
\end{tabular}

$\begin{array}{lllllllllll}0 \% & 10 \% & 20 \% & 30 \% & 40 \% & 50 \% & 60 \% & 70 \% & 80 \% & 90 \% & 100 \%\end{array}$

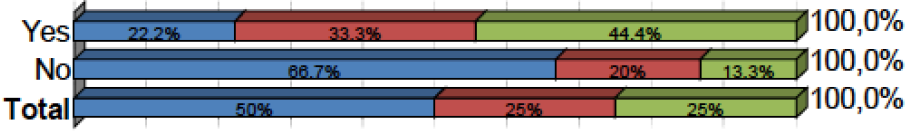

Shared Meanings Knowledge Creation (SMeKC)

Platforms (Technology) vs. SMeKC.2

Did you learn anything new from your team mates?

\begin{tabular}{|l|r|r||cr|r|}
\hline & Computer & $\begin{array}{c}\text { Immersive } \\
\text { Bubble }\end{array}$ & $\begin{array}{c}\text { Multitouch } \\
\text { Table }\end{array}$ & \multicolumn{2}{|c|}{ Total } \\
\hline Yes & $\mathbf{9}$ & $\mathbf{3}$ & $\mathbf{3}$ & $\mathbf{1 5}$ \\
\hline No & $\mathbf{3}$ & $\mathbf{3}$ & $\mathbf{3}$ & $\mathbf{9}$ \\
\hline Total & $\mathbf{1 2}$ & $\mathbf{6}$ & $\mathbf{6}$ & $\mathbf{2 4}$ \\
\hline
\end{tabular}

$\begin{array}{lllllllllll}0 \% & 10 \% & 20 \% & 30 \% & 40 \% & 50 \% & 60 \% & 70 \% & 80 \% & 90 \% & 100 \%\end{array}$

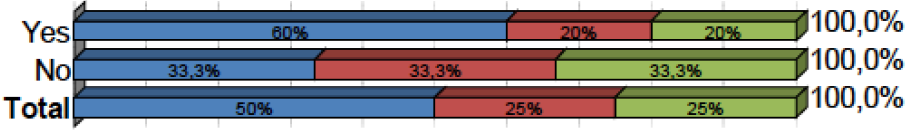

Figure 7. Results for SMeKS.2 and SMeKC.1\&2 properties, generated by Sphinx V5 software. 


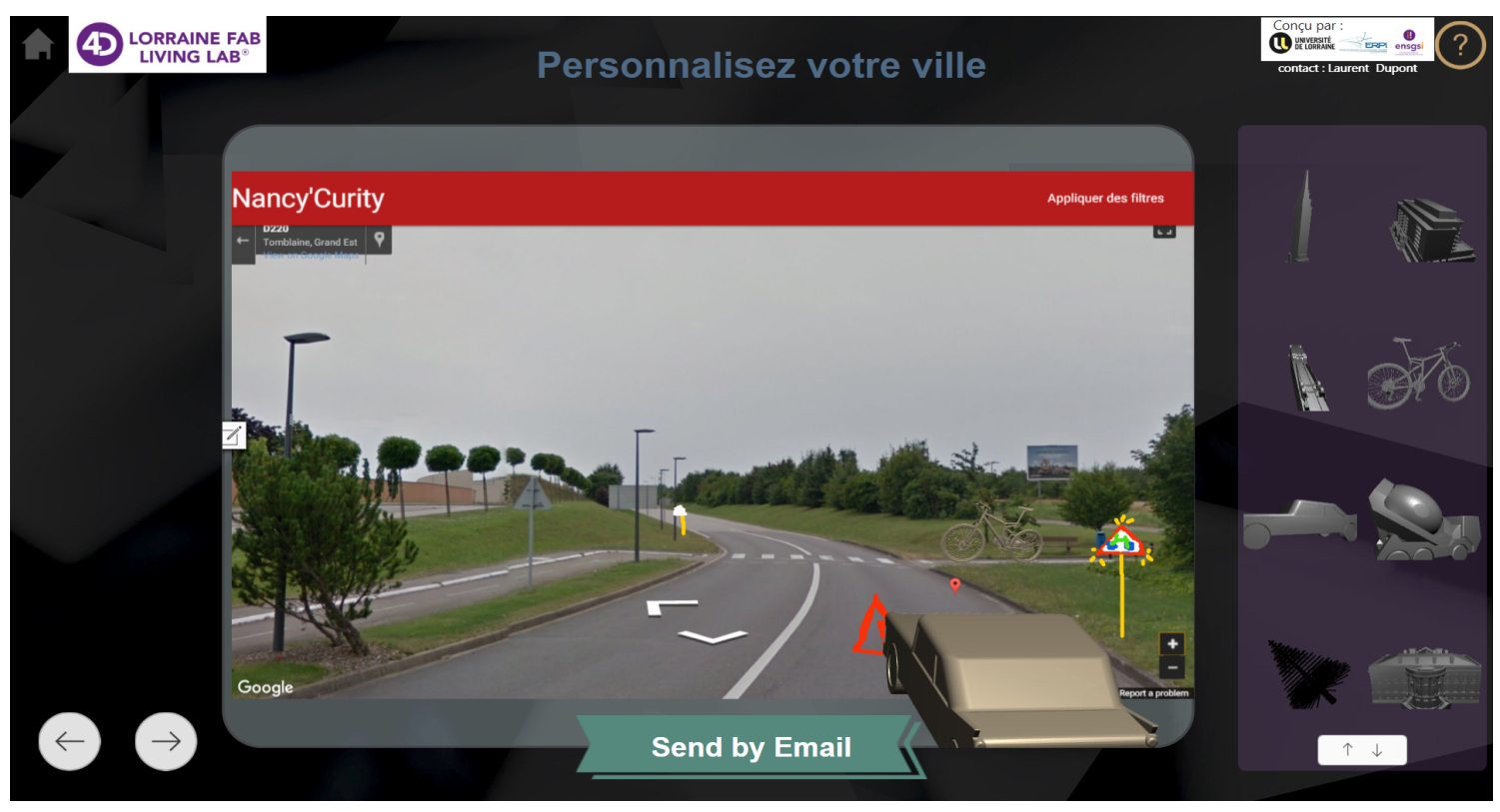

Figure 8. One co-creation generated with Multitouch Table platform and its experimental interface. 


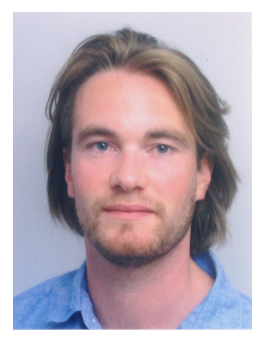

Laurent Dupont, Eng. PhD. is senior researcher at ERPI (Research Team on innovative Processes, Université de Lorraine, France), lecturer at ENSGSI and visiting lecturer at TELECOM Nancy. He is the co-founder (2014) and scientific manager of the Lorraine Fab Living Lab ${ }^{\circledR}$ (www.LF2L.fr), the ERPI research platform for prospective assessment of innovative usages and innovation acceptability. He is also the co-designer and scientific coordinator of "Lorraine Smart Cities Living Lab" (ENoLL member since 2010), an interdisciplinary project involving several laboratories and other public and private partners. $\mathrm{He}$ designs, implements and evaluates new processes, based on collaborative innovation involving users, companies and territories, generating smart and sustainable Cities. Contact:

1.dupont@,univ-lorraine.fr

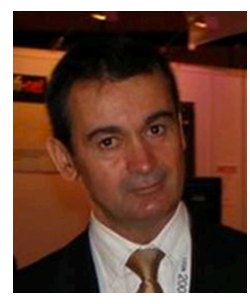

Marc Pallot, PhD. University of Nottingham. Marc spent about 20 years in the industry with different positions and responsibilities on innovation management, product design, product marketing \& engineering in different sectors: Telecom, IT, Defence, and Aeronautics. He was also a serial entrepreneur acting as co-founder of several start-ups. Since 2000, he is a senior research associate at the Centre for Concurrent Enterprise, Nottingham University Business School, and at Arts et Métiers ParisTech LAMPA P\&I team, as well at Jyväskylä University of Applied Sciences. His research domain covers User eXperience, Immersive Technologies and User-Centred Design \& Innovation within Start-ups, Living-Labs, and Smart-Cities. He is regularly involved in EU research projects since 1996. Contact: marc.pallot@ensam.eu

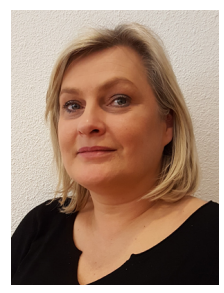

Laure Morel, Pr., Manager of the ERPI Laboratory. Laure is Director of the ERPI research team and co-founder of LF2L platform. She has led research on innovation engineering and the development of decision support tools for more than 20 years. She is one of the team members 
who invented the "PII - Potential Innovation Index" method used by Innovation Way. She is a member of the French delegation to the "ISO TC 279- Innovation Management Systems" Committee and is particularly active in the "Assessment" group. Contact: 1aure.morel@univlorraine.fr

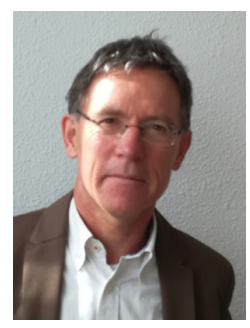

Vincent Boly, Pr, Vincent is an expert in managing innovation. He has been a University professor for 20 years and before that he spent 10 years as an engineer in industry and commerce. He was also involved in founding an Engineering School specialising in innovation (ENSGSI, Nancy). He participates in standardisation committees and has been involved in particular in developing European standards (CEN/TS 16 555). Contact: vincent.boly@univ-lorraine.fr

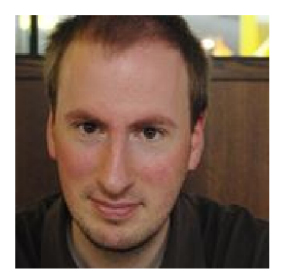

Olivier Christmann, is an associate professor in the LAMPA EA 1427 research laboratory belonging to Arts et Métiers ParisTech of Laval, France. He is director of a Master's course in Virtual Reality and Innovation. His current researches are focused on VR/AR and emerging technologies. He is interested in natural user interaction and in user experience. Contact: Olivier.Christmann@ensam.eu

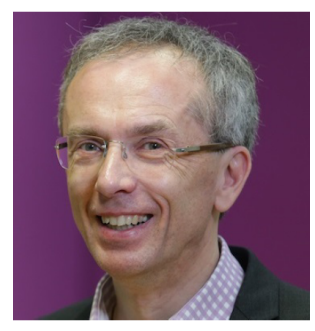

Simon Richir, M.Eng, Ph.D., one of the pioneers and the most recognized leaders in French VR research and its practical application. Professor at ENSAM (Arts \& Metiers ParisTech), the renowned French School of Engineering, Simon Richir is also the head of "Presence \& innovation" research team (LAMPA Lab, EA1427). His research and teaching activities concentrate on technological innovation, engineering design process, innovative projects, and innovative uses of new advanced technologies such as Virtual Reality or Augmented Reality. In addition to these activities, he is also the co-founder and the present scientific chair of one of the world's most prestigious international events in Virtual Reality: the annual Laval Virtual International Conference. Contact: simon.richir@ensam.eu 